\title{
The Concept and Context of Distance Learning in the New Normal Learning Scheme
}

\author{
Ronnie Jay S. Darang ${ }^{1}$, Januard D. Dagdag ${ }^{2}$ \\ ${ }^{12}$ Isabela State University \\ * e-mail: januard.d.dagdag@isu.edu.ph
}

\begin{abstract}
Distance Learning has been around since its advent in 1960 and evolved in the creation of the World Wide Web (WWW) in 1991 with the introduction of the first education programs through the internet of the University of Phoenix and other universities and colleges. The vast ideas of concepts, theories, and context have aroused the popularization and implementation of distance learning in the educational system and its first and most adversaries are those in favor of the lecture style of teaching. At the onset of the COVID19 , all fields of society have been affected and one of them is the educational system. This pandemic propagated the rise of distance learning in the Philippines and it becomes the most reliable modality of continuing the academic years. Distance learning becomes more adaptive and effective with the help of flexible teaching and learning modalities. Several studies exposed the concepts and theories for distance learning to be more acceptable. These concepts and theories are supported by the literature with claims of the context of distance learning to create an open and good system. Frameworks and being literate with the aid of continuous studies in this rising field is one of the key concepts in creating more possibilities to attain the quality of sufficient distance learning modality.
\end{abstract}

Keywords: Concept; context; distance learning; new normal; Philippines; policy

How to cite : Dagdag, J., \& Jay S. Darang, R. (2021). The Concept and Context of Distance Learning in the New Normal Learning Scheme. Pedagogi: Jurnal Ilmu Pendidikan, 21(2), 149-153. https://doi.org/https://doi.org/10.24036/pedagogi.v21i2.1183

CC 1 Licensees may copy, distribute, display and perform the work an make derivative and remixes based on it only if they
give the author or licensor the credits (attributtion) in the manner specified by these. Licensees may copy, distribute,
display, and perform the work and make derivative works and remixes based on it only for non-commercial purposes

\section{INTRODUCTION}

Since early 2000 , distance learning has popularized in the Philippines with the continuing advancements of technology. It significantly benefits all human engagements, especially in academics that bridge the gaps and barriers such as distance and time in e-learning. Yet distance learning is not a new term in the field but rather arise and can be traced back from 1960 in the University of Illinois, USA that was back then the internet hasn't been invented but through computer terminals which are interlinked and forms a network (Sarkar, 2020). Suddenly, after exposing the World Wide Web in 1991, the University of Phoenix introduced the first education programs offering through the internet that other universities and colleges started to adopt and experiment with online courses (Kentnor, 2015). Throughout then, the internet hasn't only the way to deliver learning to students, the burgeoning of radio and the development of television during World War I in the 1900s, and traditional classes found its way to a new form of education. Distance learning has become a fundamental opportunity to modify the learning setting and instructional delivery. 
The advent of COVID-19 pandemic popularized the rising field of distance learning and became the most reliable modality of continuing the academic years. Distance learning becomes an effective way to deliver instructional systems throughout nations with the limitation and restrictions of quarantine rules in the new normal scheme. In the Philippines, the beginning of distance learning has become a crucial and controversial topic that resulted in multiple debates about its causes. Its implementation has become open wide available to all the opinions and perceptive arguments of the government, the students, and parents. The problem is that concepts built by arguments are merely scratches of the context of distance education that started clashes of perspectives. For some stakeholders, either distance learning or its implementation is indeed questionable.

Hence, this article aims to provide insights to the implementation of distance learning. It discusses the primary theories on distance learning and their suggestions to the instructional process. The article also highlights the sources of predicament to adopting distance learning in the Philippine higher education institutions and offers some ways to overcome them.

\section{DISCUSSIONS}

Many studies have already exposed the concepts and theories of distance learning since its beginning years. The growing modifications of technology prompted the larger volume of distance education which is essential to the students who are studying and the distance is the problem. Yet, these aren't just the concept of distance learning but rather bountiful in ideas. The integration of developmental technology has romanticized the implementation of distance learning but for some reason, the field of instructions unveils a fragmented conceptual framework and its literature that shows the lack of foundation in theories and research. This is the challenge of acceptability and recognition of traditional academic community in distance learning.

Identifies three historical approaches of distance learning. His description of its main task as re-integrating the teaching acts (regarded as divided by the very nature of distance education) and empathy as the optimal condition for the effective presentation of learning matter and helpful student-tutor interaction (Keegan, 1986). His theory asserts that there is an active interaction between the teacher and the learners through the distance learning utilizing the internet and other modes of instructions.

Meanwhile, the theories of autonomy (Wedemeyer, 1981) and independence (Moore, 1972), highlight the vital role and crucial independence of the learner. The theories focus on the development and enrichment of learning alone by the student which is one of the components of distance learning. Its nature as distance and other factors act as the gaps in doing traditional classroom setting. The independence of the learner produces a wide range of production of ideas which is drawn by the learner. Wedemeyer suggests that greater student responsibility, widely available instruction, effective mix of media and methods, adaptation to individual differences, and a wide variety of start, stop, and learn times are essential elements of independent learning (Wedemeyer, 1981).

Holmberg supports the idea of Wedemeyer in a call for the foundation of a theory construction that revolves around the concepts of independence of the learner, learning and teaching system (Holmberg, 1989) (Wedemeyer, 1981). He summarizes his theoretical approach by stating that distance learning is a concept that covers the learning-teaching activities in the cognitive and/or psychomotor and affective domains of a learner and a supporting organization. It is characterized by non-contiguous communication and can be carried out anywhere at any time, which makes it attractive to adults with professional and social commitments (Holmberg, 1989, p. 168). Proposes and works in the theory of industrialization that contemplates the endeavor of industrialized perspective of distance learning form of teaching and learning process (Peters, 1971) .

Garrison and Shale include in their essential criteria for formulation of a distance education theory the elements of noncontiguous communication, two-way interactive communication, and the use of technology to mediate the necessary two-way communication (Garrison \& Shale, 1987). 
This theory supports the Keegan's idea of a helpful and active communication or interaction between teachers and learners.

On the other hand, the traditional classroom setting also called traditional learning system depicts that the teachers and learners are in a classroom setting with a face-to-face discussion or teaching and learning process. Distance learning place a role to make distances and time not an excuse for education which have been criticized and questionable to others because of its lack of foundation and literature support. Since the dawn of technological advancements and distance learning is utilization of gadgets that uses internet connectivity to bridge the teacher and learner, teachers are considered to be literate about the advantages of using these techs to incorporate in their teaching.

The following 6 healthy practices in distance learning (Schlichtmann, 2020) shares.

1. Clarify expectations and engagement. In the recent implementation of distance learning, online learning is neither the mode nor the modular medium teachers use. Discussing the teachers' expectations on how teaching and learning process will occur will surely be helpful for both sides in attaining a balance and healthy communications.

2. Allow for asynchronous learning. Online learning must not be the $100 \%$ medium for teaching and learning process because there are many factors that cause various effects for both the teachers and students. Asynchronous learning also helps for a better and less inconvenient ways of mastering learning.

3. Assign note-takers. Videos are sometimes inconvenient for other students because of perceiving factors such as internet connectivity. Notes such as modules are very helpful material in learning.

4. Make materials accessible. Since not all the time, every student has the same opportunity and level of possessions that hinders others to access information or the materials needed for the learning process. Teachers must create a way of giving the instructions that all at the same time can access the materials.

5. Embrace students as teachers. Students in the distance learning must not be spoon-fed of information but rather tasked to display a creative act through interactive and authentic activities. This enables the teacher to gather feedback and evidence that are helpful in planning and evaluating for further improvement of instructions.

6. Actively build a supportive community. Unlike traditional classroom setting where a teacher can always observe the emotional and physical well-state of the students, in distance learning a supportive community must be established in order to maintain a healthy process of teaching and learning that provides self-esteem for others to perform well and excel.

The teaching and learning process in distance learning as the crucial part must be intensively founded with sufficient materials that integrate students and teachers in the process. Otto Peter's theory suggests that for an effective teaching and learning process, the teaching process in his theory of industrialization is gradually restructured through increasing mechanization and automation while courses must be formalized and expectations of students must be standardized (Peters, 1971). This is what (Schlichtmann, 2020) conveys as she explains the practice of "Explicitly teach expectations and engagement" that establishes a parallel concept of the interaction and groundwork of the teaching and learning plan.

Moreover, teachers are not just teaching but also care for the welfare of the learners. This supports Keegan's theory that denotes historical approach in line with the distance learning that re-integrates the teachers' competence and skills with the teaching and learning process with empathy as the optimal condition for the effective presentation of learning matter and helpful student-tutor interaction. It is how (Schlichtmann, 2020) refers to the practice of "Actively build a supportive community" that creates an open environment for teaching and learning process without hesitations of regarding the well-being of the learners. This is because different learners have different characteristics and life challenges which sometimes a cause of misinterpretations in 
attitudes and perceptions. There are also instances that the performance of students in class is affected with these underlying emotional and physical welfares.

Furthermore, even in the traditional classroom setting, the teachers give time for students to produce ideas, concepts and perform with their own understanding of the instructions given. This is an execution of the theory of autonomy and independence presented by (Wedemeyer, 1981) and (Moore, 1972). There are often times teachers over-feed students with information or instruction that they tend to turn the class into a lecture style of teaching and learning process that limits the capability of learners to draw new and innovative ideas, share their opinions and thoughts that according to (Wedemeyer, 1981) and (Moore, 1972)are a significant component of distance learning in their theory. Schlichtmann supported this theory with the practice of "Allow for asynchronous learning" which she explains that teachers must pa ve way for the learners to explore and discover a vast, wide and limitless interconnected ideas, perspectives and thoughts (Schlichtmann, 2020), (Holmberg, 1989) supported the theory of (Wedemeyer, 1981) and claims the theory construction which he stated focuses on the development of the learners in psychomotor, cognitive and affective domains. Schlichtmann reinforced this theory with the practice of "Assign note-takers" and "Make materials accessible". Allowing students to study on their own time and capability with the materials being available at all times such as video presentations and documents or modules is a significant concept of distance learning that is beneficial to create self-directed learners (Schlichtmann, 2020).

Distance learning is not a one-way ticket that delivers a message. It is a two-way communication that promotes an interactive communication between the teacher and the learners (Garrison \& Shale, 1987). To strengthen this theory, (Schlichtmann, 2020) proposes the practice of "Embracing students as teachers" by allowing students to be a part of not just learning but also instructional planning. That is, students should have the opportunity to give an honest and sincere feedback about their learning and the teaching. Schlichtmann believes that when teachers are informed about the students' feedback, they can adapt instruction to a more adaptive, responsive, and outcomes-oriented one (Schlichtmann, 2020).

\section{The Predicament}

During the community lockdown of all mass gatherings around the Philippines and the temporary academic freeze to limit the transmission of the COVID-19 virus, two ideas dominates the poll for deciding about the continuation of Academic Year(s). Vast of contradicting ideas debated for what should happen. Some wanted that the government would initiate a permanent academic-freeze until the end of the pandemic, some pushes through and wanted to continue studying despite of the challenges through Distance Learning. This is one of the biggest issues that the government, students, teachers and parents have argued about. Yet, continuation prevails and distance learning as the most flexible, efficient and available way to execute the teaching and learning process started. Teachers and students are not confidently prepared in this modality but the main point is misconceptions.

With the discussion, there are statements discussing the lack of foundation and a fragmented framework of distance learning. This is the biggest complication all concerned persons are facing, a big misconception with the hitch of implementation. There are many perceptions of the concepts of distance learning which have become a source of predicament. One is that distance learning is $100 \%$ (pure) online teaching and learning setting.

\section{CONCLUSION}

The solution needed for this predicament is the whole context and development of distance learning. Educating and/or informing about the framework and continuous studies create a possibility to make distance learning an effective modality of learning. To eliminate the misconceptions and allow a good implementation, further studies most especially in this time will be a great benefit, an advantage to enlighten all concerned persons to the underlying struggles 
sought by teachers and students. The utilization and maximization of theories and studies available are all helpful to attain a quality distance learning modality.

\section{REFERENCES}

Garrison, D., \& Shale, D. (1987). Mapping the Boundaries of Distance Education: Problems in Defining the Field. The American Journal of Distance Education, 1(1), 7-13.

Holmberg, B. (1989). Theory and Practice of Distance Education. Routledge.

Keegan, D. (1986). The Foundations of Distance Education. Croom Helm.

Kentnor, H. E. (2015). Distance Education and the Evolution of Online Learning in the United States. Curriculum and Teaching Dialogue, $17(1 \& 2)$.

Moore, M. G. (1972). Learner Autonomy: The Second Dimension of Independent Learning. Convergence Fall, 76-88.

Peters, O. (1971). Theoretical Aspects of Correspondence Instruction. in O. Mackenzie \& E. L. Christensen (Eds.), the Changing World of Correspondence Study University Park. Pennsylvania State University.

Sarkar, S. . R. from http://bit. ly/3eYEpX. (2020). A Brief History of Online Education. Adamas University. http://bit.ly/3eYEpX1

Schlichtmann, G. (2020). Distance Learning: 6 UDL Best Practices for Online Learning. https://u.org/3qYGxAk

Wedemeyer, C. (1981). Learning at the Backdoor. , WI: University of Wisconsin Press. University of Wisconsin Press. 